\section{Genotyping of Human Papilloma Virus (HPV) in female condyloma acuminata patient in Dr. Soetomo Hospital, Surabaya}

\section{Afria Arista, Dwi Murtiastutik, Trisniartami Setyaningrum, Gondo Mastutik}

Department of Dermatology and Venereology, Universitas Airlangga, Dr. Soetomo-Teaching Hospital, Surabaya, Indonesia

\begin{abstract}
Human Papilloma Virus (HPV) cause the most common sexually transmitted infection in women. HPV may lead to clinical manifestation as condyloma acuminata. The type of HPV are divided into two categories: low risk and high risk. Objective: To determine the type of HPV in female condyloma acuminata patient. A cross sectional study was conducted in Dermatology Venereology Outpatient Clinic Dr. Soetomo Hospital Surabaya from February, 2007 to May, 2007. A total of 13 female patients with condyloma acuminata were includ in this study. Nucleic acids amplification assays (Polymerase Chain Reaction) used to detect the HPV infection. Condyloma acuminata mostly caused by HPV-11 (30,76\%) and HPV-6 (23,07\%). Only 1 patient in this study caused by HPV 18. $38 \%$ of condyloma acuminata in this study caused by multiple infection of HPV. Molecular assay are gold standard to identification of HPV in the condyloma acuminata patient.
\end{abstract}

\section{Introduction}

Condyloma acuminata is one of the sexually transmitted diseases that often occur in the general population. Condyloma acuminata often occur in active sex group at the age of 15 to 24 years. The prevalence of condyloma acuminata in Dr Soetomo Hospital Surabaya in 2013-2015 as much as $8,6 \%$. Low risk HPV (HPV types 6 and 11) rarely give rise to cervical cancers. Infection by low risk HPV is responsible for 90 percent of the cases of condyloma acuminata. Otherwise, high risk HPV (HPV types 16 and 18) are associated with malignancy. The presence of HPV infection in patient can be inferred from clinical finding, serological, and morphological.
The diagnosis of HPV can be established by molecular biology techniques that allow its accurate detection. At present, nucleic acidhybridization assays, signal-amplification assays and nucleic-acid amplification are available to detect the HPV infection. Polymerase Chain Reaction (PCR) is one of the techniques using nucleic acid amplification methods which has high sensitivity and specificity.

\section{Materials and Methods}

A cross sectional design study using a PCR to detect the type of HPV in genital lesion of 13 female condylomata acuminata patients in Dermatology Venereology Outpatient Clinic Dr. Soetomo Hospital Surabaya from February 2007 to May 2017. 13 sample of condyloma acuminata were taken by biopsy from labium majus, perineum, and labium minor. The PCR using Ampliquality HPV Type Express v.3.0 (single step PCR and Reverse Line Blot) which can detect 40 type of HPV. In this study the PCR using fresh tissue from the biopsy sample. After an initial denaturation step at $95^{\circ} \mathrm{C}$ for 10 minute, followed by hybridization (incubated under specific conditions with a solution containing the labeled and denaturated PCR product), washing (unbound PCR product is washed away), and visualization based on the type of labeling used.

\section{Results}

of Study conducted on 13 samples condyloma acuminata. All sample meet the requirement and are willing to participate in
Correspondence: Afria Arista, Department of Dermatology and Venerology, Faculty of Medicine, Universitas Airlangga/Dr. Soetomo General Hospital, Prof Dr Moestopo 47, Surabaya, Indonesia.

Tel.: +628123464828.

E-mail: afria.kayla@gmail.com

Key words: condyloma acuminata, HPV, female.

Contributions: All the authors contributed equally

Conflict of interest: There is no potential conflict of interests in this study.

Received for publication: 1 February 2019. Accepted for publication: 13 February 2019

This work is licensed under a Creative Commons Attribution-NonCommercial 4.0 International License (CC BY-NC 4.0).

(C) Copyright A. Arista et al., 2019

Licensee PAGEPress, Italy

Dermatology Reports 2019; 11(s1):8062

doi:10.4081/dr.2019.8062

the research by signing informed consent and information for consent. Condyloma acuminata mostly caused by HPV type 6 and 11.The result in this study, from 13 patient with condyloma acuminata, 8 patient has single infection of HPV. 7 patient with low risk HPV (3 patient with HPV type 6, 4 patient with HPV type 11). 1 patient with high risk HPV (HPV type 18). In this study 5 patient has multiple infection of HPV. 1 patient $(7,6 \%)$ with HPV type 6 , $42,51,61.1$ patient $(7,6 \%)$ with HPV type $6,81,82,89.1$ patient $(7,6 \%)$ with HPV

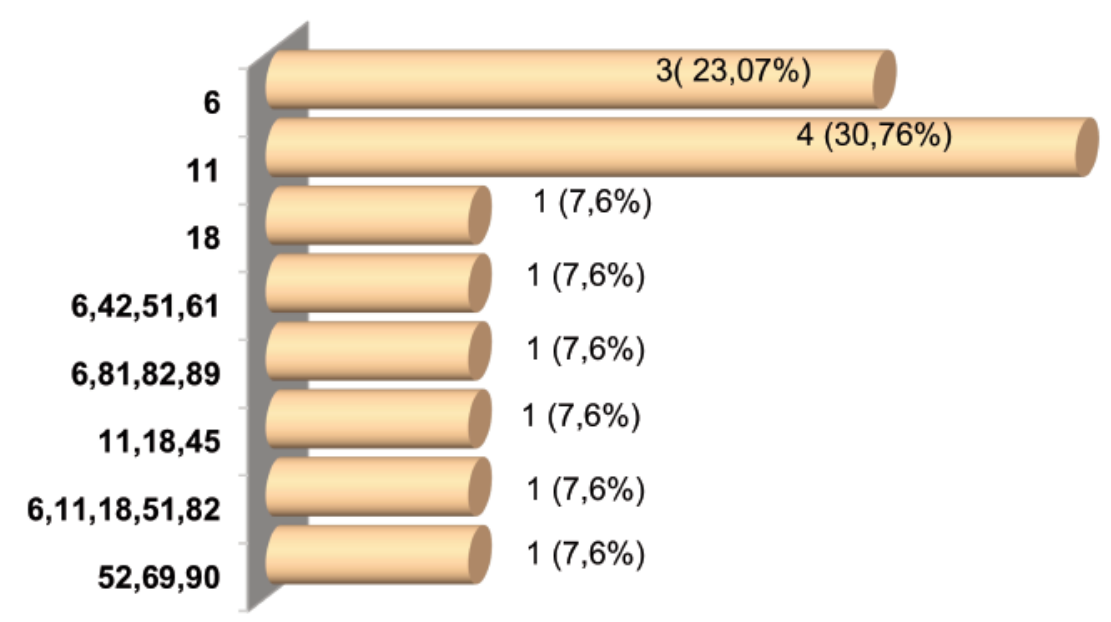

Figure 1. Distribution of HPV in genital lesions of condyloma acuminata patient in Dr. Soetomo Hospital Surabaya. 
type $11,18,45.1$ patient $(7,6 \%)$ with HPV type $6,11,18,51,82$, and 1 patient $(7,6 \%)$ with HPV type 52, 69, 90 (Figure 1).

\section{Discussion}

HPV infection can cause lesions in human skin and mucous membrane. HPV genital infection is transmitted primarily through sexual contact. HPV infection is one of the common sexually transmitted infections in the world. HPV can cause cervical cancer, particularly the high risk HPV genotypes. It was very important to detect the genotype of HPV for the patients with genital warts or cervical lesions. ${ }^{1}$

Molecular detection is a gold standar to identify HPV infection. There are 3 kind of classification to HPV test: (1) Nucleic acids hybridization assays, (2) Signal amplification assays, and (3) Nucleic acids amplification assays. PCR is a part of Nucleic Acids Amplification Assays. The benefit of Nucleic Acids Amplification Assays are flexible technology (viral load and genotype), very high sensitivity, and multiplex analysis., ${ }^{2,3}$

In this study we used a tool Ampliquality HPV Type Express v.3.0. The PCR allows identification of the following HPV genotypes: HPV 6, 11, 16, 18, 26, 31, 33, $35,39,40,42,43,44,45,51,52,53,54,55$, $56,58,59,61,62,64,66,67,68 \mathrm{a}, 68 \mathrm{~b}, 69$, $70,71,72,73,81,82,83,84,87,89,90$. risk genotypes, such as HPV 6 and 11 . Multiple HPV infections with more than one HPV.

Ninety percent of condyloma acuminata caused by two low oncogenic genotype are common. ${ }^{4}$ The results of this study in Dr. Soetomo Hospital Surabaya 3 patient with HPV type 6.4 patient with HPV type 11, and 1 patient with high risk HPV (HPV type 18). In this study 5 patient has multiple infection of HPV. 1 patient with HPV type $6,42,51,61.1$ patient with HPV type 6, 81, 82, 89. 1 patient with HPV type 11,18 , 45. 1 patient with HPV type $6,11,18,51$, 82, and 1 patient with HPV type 52, 69, 90. The results of this study are consistent with previous studies conducted in China from September 2009 to August 2013 in Peking University Shenzhen Hospital show the result that the common low risk HPV genotypes were HPV 6 (16,98\%), and HPV $11(11,09 \%)$. The most common high risk HPV genotypes were HPV 16, 52, 58, 56, 18,66 and 33 . $38.02 \%$ patient with multiple infection (low risk mixed with high risk HPV). ${ }^{5}$

\section{Conclusions}

Molecular assay are gold standard to identification of HPV in the condyloma acuminata patient. Condylomata acuminata mostly caused by single infection of HPV type 6 and 11, but this study showed that
$38 \%$ patient with condylomata acuminata caused by multiple infection of HPV. It is very important to perform HPV examination in condyloma acuminata patient to know the possibility of malignancy in patient .

\section{References}

1. Patel RV, Yanofsky VR, Goldenberg G. Genital warts: a comprehensive review. J Clin Aesthet Dermatol 2012; 5(6): 25 36.

2. Abreu ALP, Souza RP, Gimenes F, Consolaro MEL. A review of methods for detect human papillloma virus infection. Virol J 2012; 9: 1-9

3. Zaravinos A, Mammas IN, Sourvinos G, Spandidos DA. Molecular detection methods of human papilloma virus (HPV). Int J Of Biol Markers 2009; 24 (4): 215-22.

4. Mzibri M, Attelab M, El Hassani RA, Khyatti M, Benbacer L, Ennaji MM, et al. Evaluation of p53, p16INK4a and E cadherin status as biomarker for cervical cancer diagnosis. In Tech 2012: 195-214

5. Li-hua LU, Jing YU, Yin-han Z, Xiafeng WU, Xiao-yi LIU. HPV infection and distribution of HPV genotypes on patients with condyloma acuminatum. J Reprod Contracept 2014; 25(1): 26-31. 